\title{
Hope for the Best, Prepare for the Worst: Response of Tall Steel Buildings to the ShakeOut Scenario Earthquake
}

\author{
Matthew Muto a) and Swaminathan Krishnan, ${ }^{\text {a) }}$ M.EERI
}

\begin{abstract}
This work represents an effort to develop one plausible realization of the effects of the scenario event on tall steel moment-frame buildings. We have used the simulated ground motions with three-dimensional nonlinear finite element models of three buildings in the 20-story class to simulate structural responses at 784 analysis sites spaced at approximately $4 \mathrm{~km}$ throughout the San Fernando Valley, the San Gabriel Valley, and the Los Angeles Basin. Based on the simulation results and available information on the number and distribution of steel buildings, the recommended damage scenario for the ShakeOut drill was $5 \%$ of the estimated 150 steel moment-frame structures in the 10-30 story range collapsing, $10 \%$ red-tagged, $15 \%$ with damage serious enough to cause loss of life, and $20 \%$ with visible damage requiring building closure. [DOI: 10.1193/1.3563621]
\end{abstract}

\section{INTRODUCTION}

In order to prepare for the next big earthquake on the San Andreas Fault, the U.S. Geological Survey (USGS) implemented a yearlong "DARE TO PREPARE" campaign that culminated in the Great Southern California ShakeOut Scenario, a large-scale earthquake response exercise, in November of 2008. The exercise was notable both for the number of participants and the level of scientific support in planning. A magnitude 7.8 earthquake on the southern San Andreas Fault was chosen as the scenario event and a detailed, realistic source model for the event was generated (Hudnut et al. 2007) and used to create simulated ground motions at locations throughout Southern California (Graves et al. 2008, 2011). Researchers used this information to estimate the impacts of the event, such as structural damage, hazards from fires following the earthquake, damage to lifelines, interruption of utilities, economic impacts and prospects for long-term recovery (Jones et al. 2008, Porter et al. 2008). In support of this effort, we were charged by the USGS with developing a plausible realization of the response of tall steel moment-frame buildings to the scenario event. Major steel building damage observed in the 1985 Mexico City earthquake, the 1994 Northridge earthquake, and the 1995 Kobe earthquake (FEMA 2000b) make it clear that any earthquake drill in Southern California should consider the possibility of serious damage to tall steel buildings, or even collapse.

In a prototype study conducted to demonstrate the feasibility of assessing the seismic hazard on a regionwide basis through earthquake simulation and structural model response history analyses, Krishnan et al. (2006) simulated the effects of an 1857-like San Andreas Fault earthquake on two steel moment-frame building models hypothetically located at 636

\footnotetext{
${ }^{\text {a) }}$ California Institute of Technology, Pasadena, CA 91125
} 
sites in Southern California. To estimate tall steel moment-frame building response in Southern California under the ShakeOut Scenario earthquake, we follow that approach, but vastly expand on the scope to provide a more credible picture of the outcome for effective seismic preparedness. We analyze three steel moment-frame buildings in the 20 -story class, orienting them in two different directions, considering perfect and imperfect realizations of beam-to-column connection behavior, subjecting them to the simulated three-component ground motions at each of 784 analysis sites in the San Fernando Valley, the San Gabriel Valley and the Los Angeles Basin spaced at approximately $4 \mathrm{~km}$, as shown in Figure 1. We use the modeled building performance to provide a quantitative picture of one plausible outcome in the event of the big one striking Southern California.

\section{THE SHAKEOUT SCENARIO EARTHQUAKE}

The event chosen was a magnitude 7.8 earthquake on the San Andreas Fault with rupture initiating at Bombay Beach and propagating northwest a distance of roughly $304 \mathrm{~km}$, terminating at Lake Hughes near Palmdale, as shown in the inset of Figure 1. The source model is constrained by the available geologic, geodetic, paleoseismic, and seismological observations and was developed through expert discussion at multiple meetings and workshops (Hudnut et al. 2007). Using this source model, Graves et al. (2008) used viscoelastic finite difference methods to simulate three-component seismic waveforms on a uniform grid covering Southern California. The SCEC Community Velocity Model (Magistrale et al. 1996, Magistrale et al. 2000, Kohler et al. 2003), which allows for the modeling of the basin response down to a shortest period of approximately $2 \mathrm{~s}$, was used for the ground motion simulations. This study uses the long-period ShakeOut v1.1 ground motions, low-pass filtered at $2 \mathrm{~s}(0.5 \mathrm{~Hz})$. Graves subsequently created broadband seismograms using a hybrid

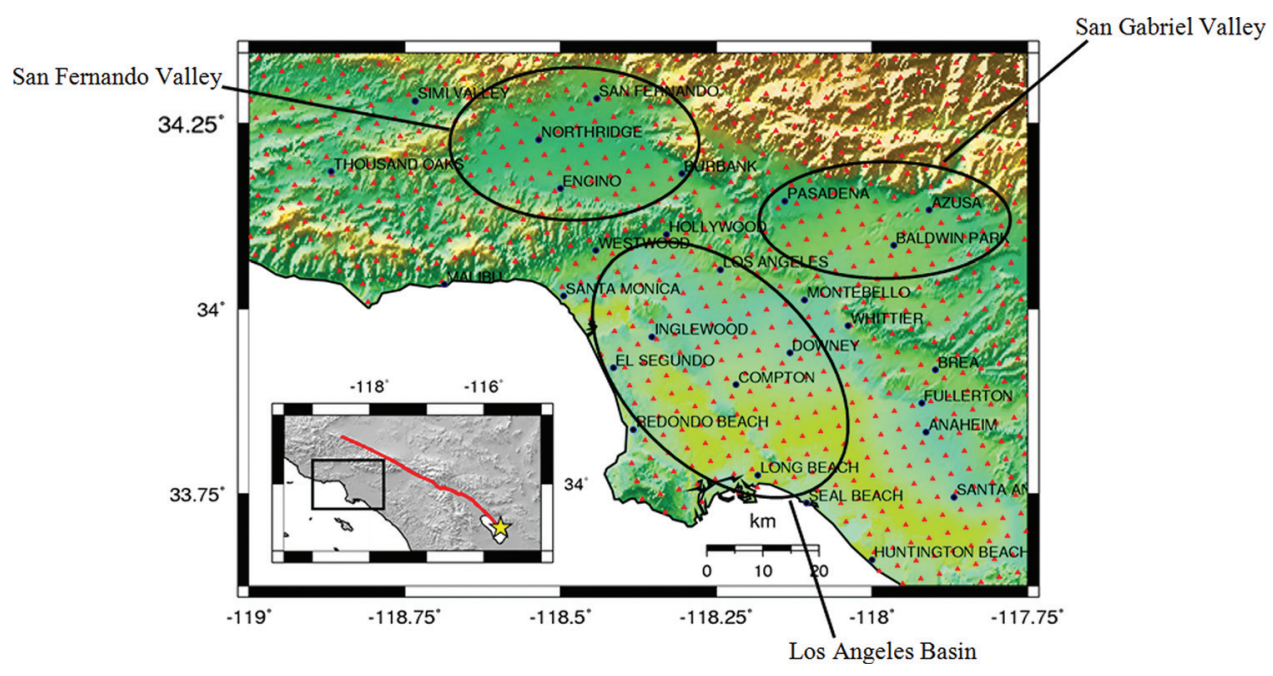

Figure 1. Geographical scope of study area. Triangles represent sites where building time-history analyses are performed. The inset shows the study area in relation to the rupture trace. The star represents the epicenter of the earthquake. 


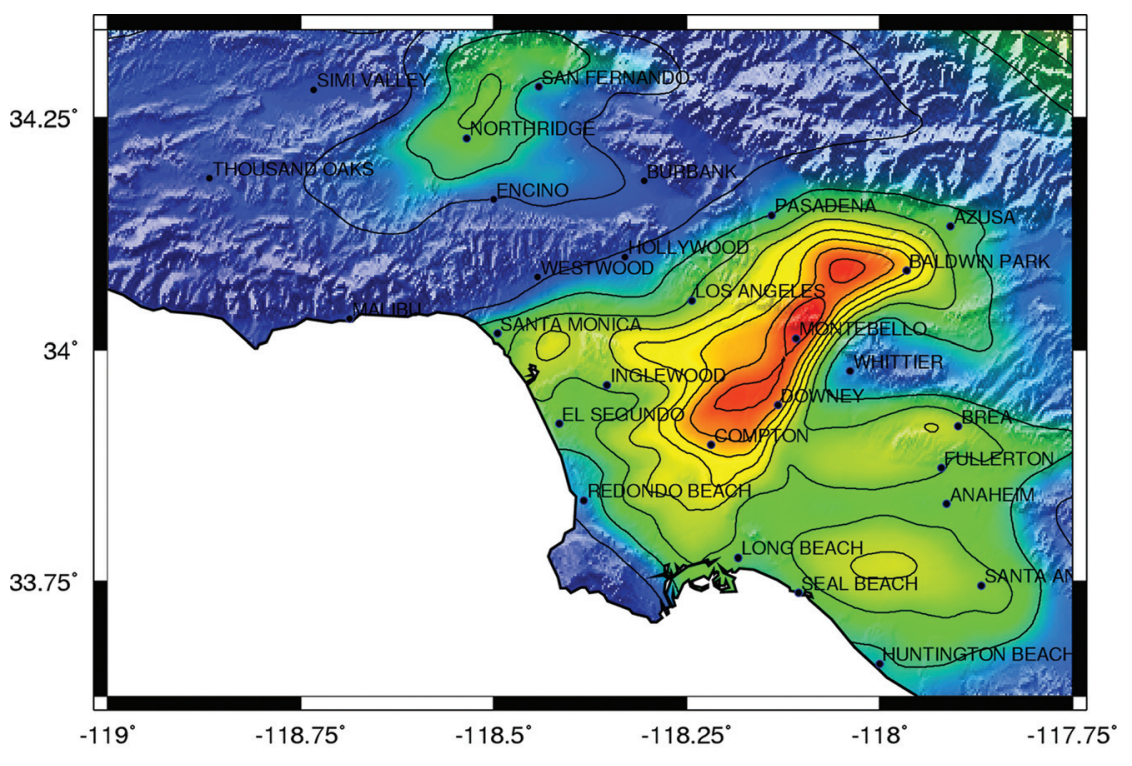

(a)
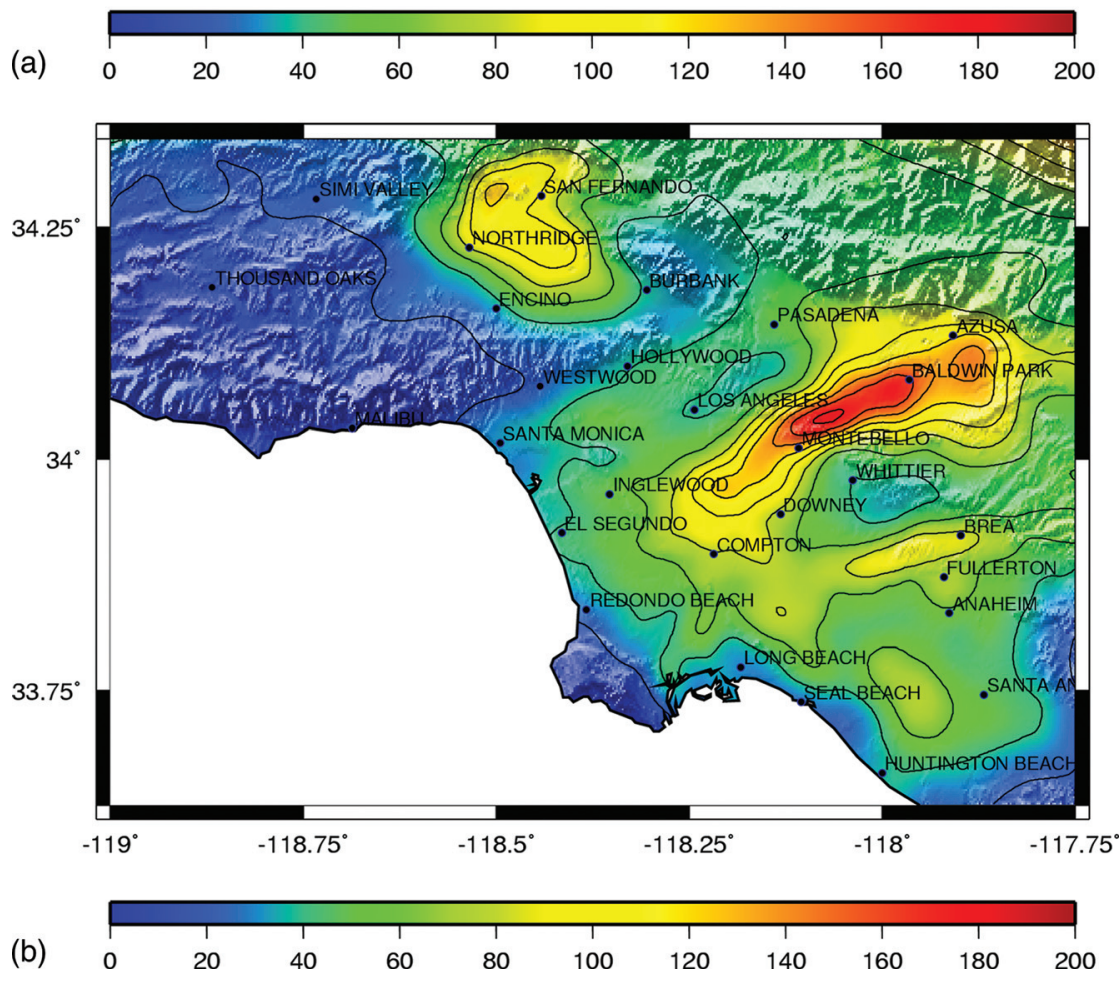

Figure 2. Peak ground velocities (in $\mathrm{cm} / \mathrm{s}$ ) for the scenario earthquake in the (a) east-west and (b) north-south directions. 
method to combine the deterministic long-period synthetics with semi-stochastic shortperiod synthetics. Unfortunately, due to the tight timeline for deliverables associated with the ShakeOut exercise, the structural analyses could not be repeated using the broadband ShakeOut v1.2 ground motion waveforms. However, the high-frequency content does not significantly alter the response of the long-period structures studied here (see Appendix A for additional discussion). Figures $2 \mathrm{a}$ and $2 \mathrm{~b}$ show the peak velocities of the simulated waveforms in the east-west and north-south directions, respectively. Peak velocities are in the range of $0-100 \mathrm{~cm} / \mathrm{s}$ in the San Fernando Valley, and $60-180 \mathrm{~cm} / \mathrm{s}$ in the Los Angeles basin. Corresponding peak displacement ranges are $0-100 \mathrm{~cm}$ and $50-150 \mathrm{~cm}$.

Velocity time histories for the east-west component of ground motion are shown in Figure 3 for seven sites near clusters of existing tall buildings and one site in a region of strong shaking. For sites in the San Gabriel Valley (Pasadena and Montebello), the duration of strong shaking is less than 50 seconds. However, as waves propagate through the soft soil of the Los Angeles basin, the resulting ground motions for sites such as Santa Monica, downtown Los Angeles, El Segundo and Long Beach feature strong shaking lasting as long as 100 seconds. Figure 4 shows the velocity response spectra (with 5\% damping) for each component of the ground motions at the same sites. At several sites, peaks are observed around $4 \mathrm{~s}$, which is close to the natural period of the buildings considered in this study. To validate the simulated
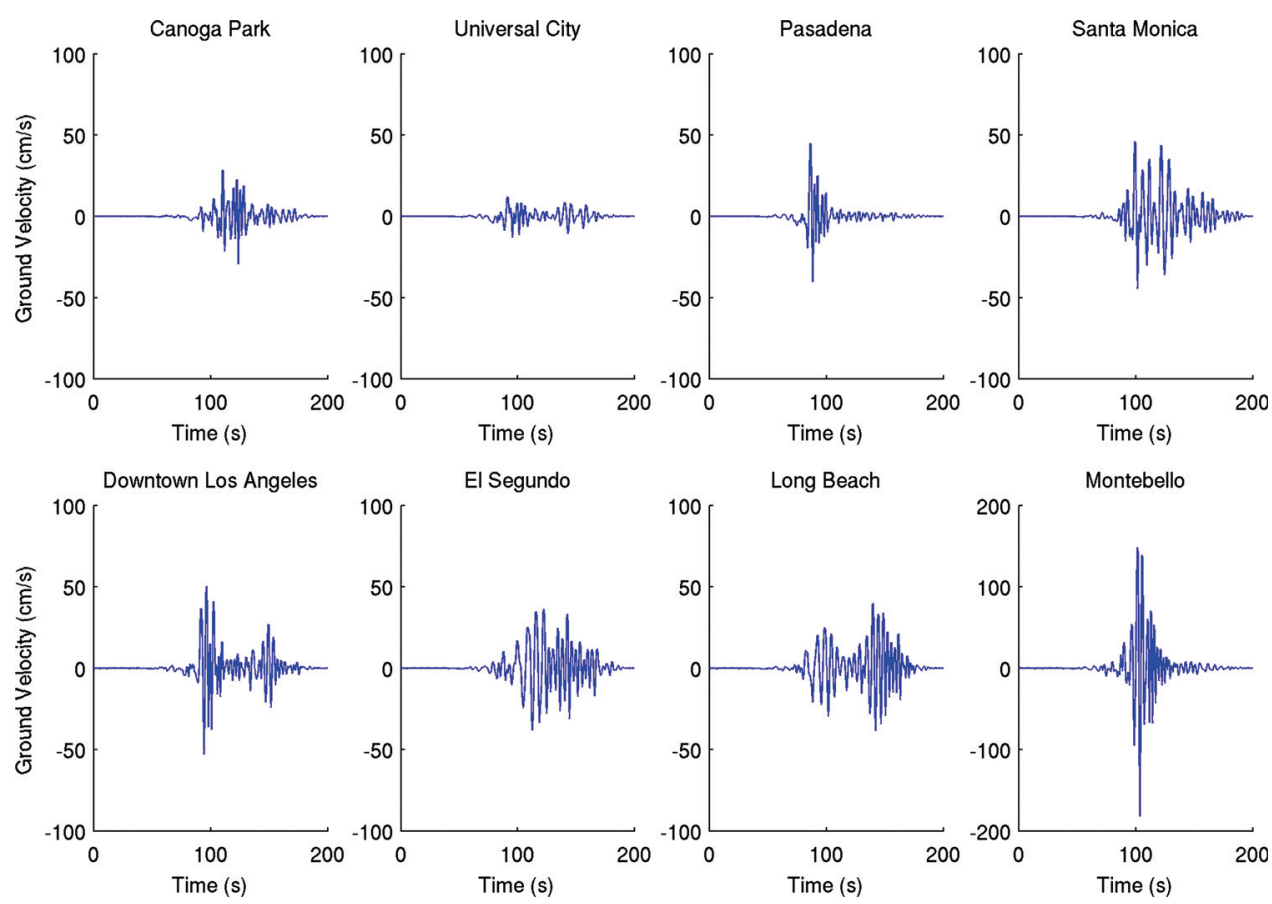

Figure 3. Velocity time histories for the east-west component of ground motion at selected sites near clusters of existing high-rise buildings (Canoga Park, Universal City, Pasadena, Santa Monica, downtown Los Angeles, El Segundo, and Long Beach) and a site located in a region of very strong shaking (Montebello). 

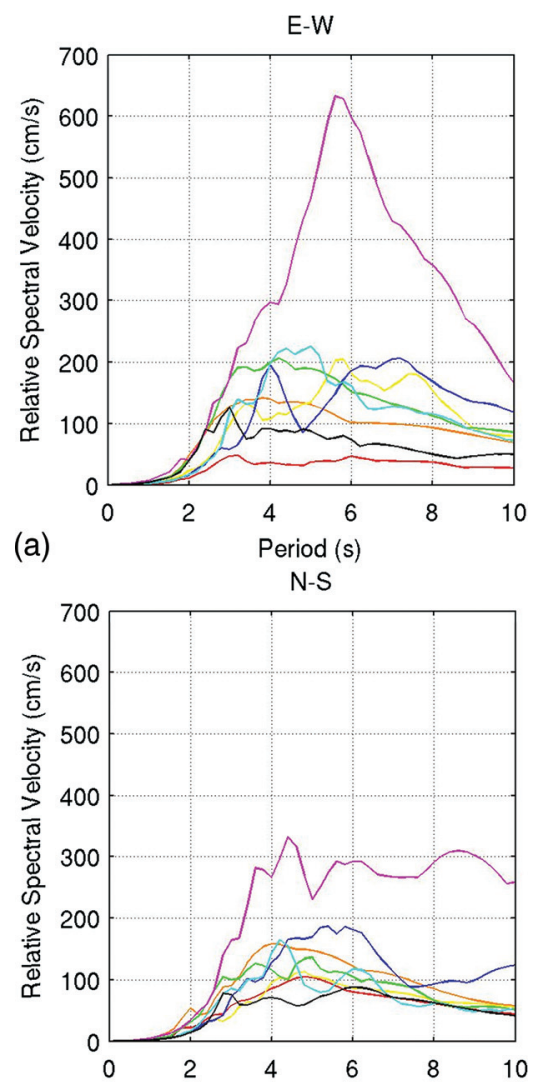

(b)

Period (s)

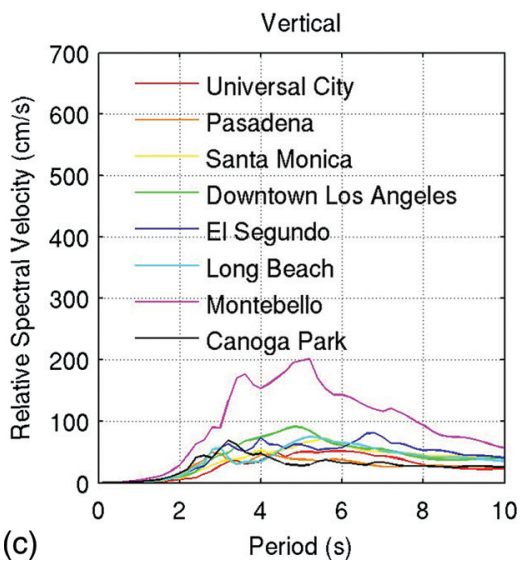

Figure 4. Velocity response spectra for the (a) east-west and (b) north-south and (c) vertical components of ground motion at selected sites near clusters of existing high-rise buildings (Canoga Park, Universal City, Pasadena, Santa Monica, downtown Los Angeles, El Segundo, and Long Beach) and a site located in a region of very strong shaking (Montebello). 
ground motion, Star et al. (2008) conducted a study comparing the statistical features of the synthetics against those of ground motion predictions using the Next Generation Attenuation (NGA) relations. They find the attenuation of long period motion from the two approaches to be similar, with the average residual of the simulated event (i.e., event term) to be 0.8 (expressed in $\log$ units) at periods of about $2 \mathrm{~s}$ to $4 \mathrm{~s}$. This value is within the scatter of event terms from actual earthquakes used in the development of the NGA equations.

\section{DESCRIPTION OF MODELED BUILDINGS}

The locations of tall buildings (ten or more stories) in the study area are shown in Figure 5. The size of circles shown in the figure is proportional to the number of stories. There are 489 buildings with 10-19 stories, 118 buildings with 20-29 stories, 28 buildings with 30 39 stories, 11 buildings with 40-49 stories, and 10 buildings with 50 or more stories. Many more are in the planning stages or under construction. It is clear that majority (607) are in the 10-30 story range. In this height range, pure lateral force-resisting systems (e.g., steel moment frames, steel braced frames, concrete shear walls) are commonplace, although dual systems cannot be ruled out for the taller buildings (20-30 story range). Here, we assume that approximately one quarter of these buildings (150) utilize steel moment frames as the primary lateral force resisting system, similar to the buildings to be considered in this study.

The buildings are clustered in small pockets that are aligned with the major freeways in the region. Most tall buildings have been built along the Wilshire corridor, parallel to the east-west traversing Interstate freeway I-10 from Santa Monica to downtown Los Angeles, and along State Highway 101 from Hollywood to Canoga Park in the San Fernando Valley. In addition a few tall buildings are located along the north-south traversing Interstate freeways, I-5 and I-405.

Structural models of three buildings are chosen to be subjected to ground motions at the 784 analysis sites. All three buildings are near 20 stories, in the middle of the 10-30 story

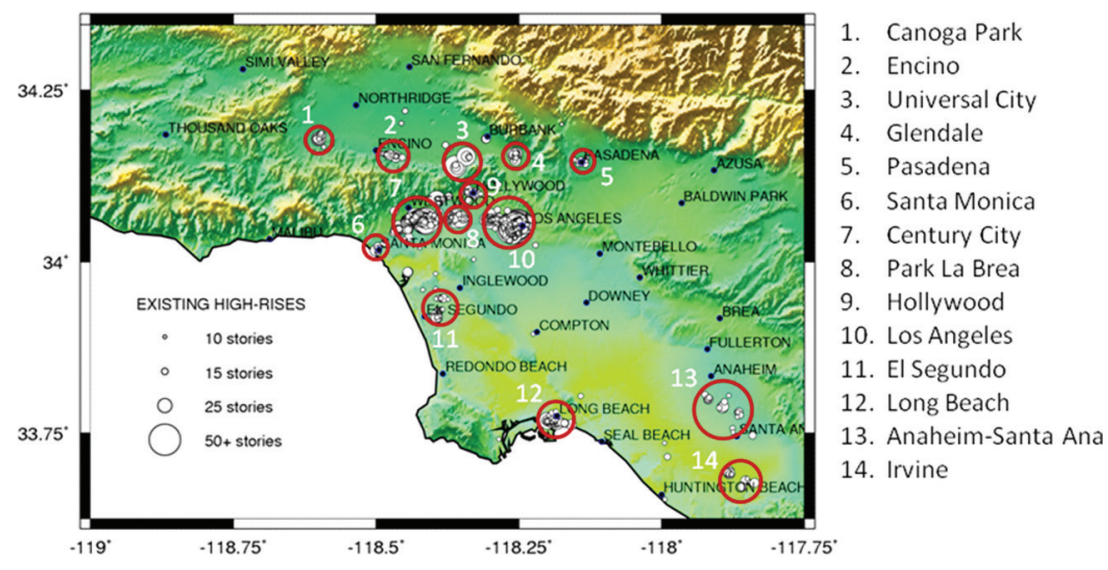

Figure 5. Distribution of tall buildings (ten stories or higher) in Southern California as of mid2007. Marker size corresponds to the number of stories. Large red circles indicate 14 identified clusters of high-rise buildings (Emporis 2007). 
range containing the majority of the existing high-rise buildings. Building 1 is based on an existing 18-story office building located within five miles of the epicenter of the 1994 Northridge earthquake. An isometric view is shown in Figure 6a. It was designed according to the lateral force requirements of the 1982 UBC and construction was completed in 19861987. The lateral force-resisting system consists of two-bay welded steel moment frames, two apiece in each principal direction of the structure as shown in Figure 6d. The location of the north frame one bay inside of the perimeter gives rise to some torsional eccentricity. Many moment-frame beam-column connections in the building fractured during the Northridge earthquake, and the building has been extensively investigated since then by engineering research groups (SAC 1995).

Building 2, shown in an isometric view in Figure 6b, is similar to Building 1, but the lateral force-resisting system has been redesigned according to the 1997 UBC. The new building has been designed for larger earthquake forces and greater redundancy in the lateral force-resisting system. Building 2 has eight bays of moment frames, although the three-bay moment frames shown in Figure 6e will dominate over the single-bay moment frames. The

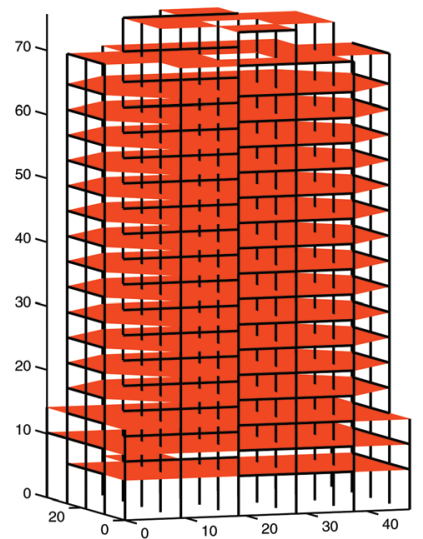

(a)

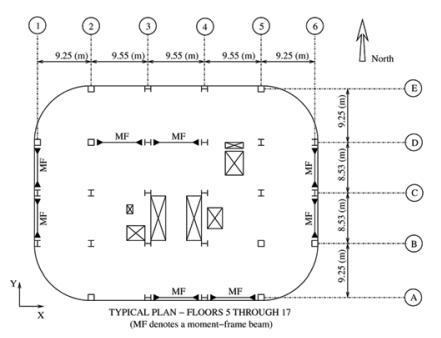

(d)

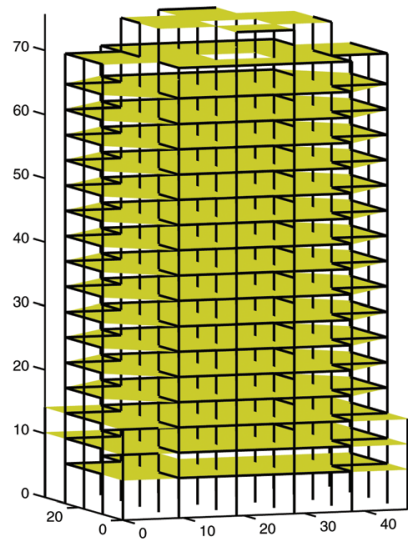

(b)

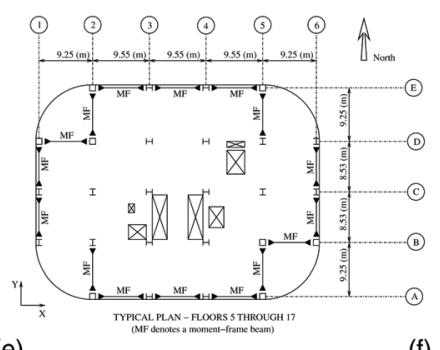

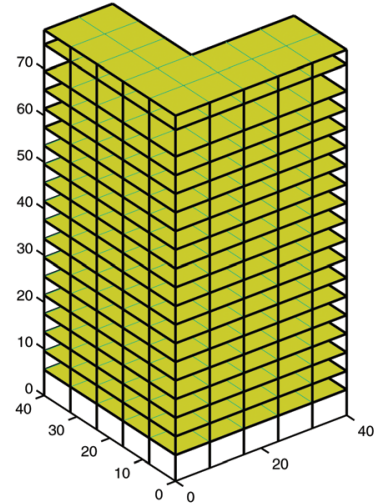

(c)

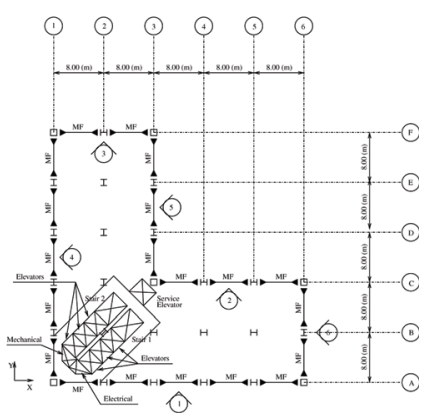

Figure 6. Building selected for structural analysis: (a) Building 1, an existing 18-story building designed according to the 1982 UBC; (b) Building 2, a redesigned version of Building 1 conforming to the $1997 \mathrm{UBC}$; and (c) Building 3, a 19-story L-shaped building designed according to the 1997 UBC. Plan views for Buildings 1, 2, and 3 are shown in (d), (e), and (f), respectively. Bays marked "MF" indicate moment frames. 
Table 1. Summary of the height, building code used for design, and fundamental modes of the three building models

\begin{tabular}{lcccccccc}
\hline \hline & & \multicolumn{7}{c}{ Fundamental Modes } \\
\cline { 4 - 9 } Model & Height & $\begin{array}{c}\text { Design } \\
\text { Code }\end{array}$ & Period & Type & Period & Type & Period & Type \\
\hline 1 & $75.7 \mathrm{~m}$ & $1982 \mathrm{UBC}$ & $4.52 \mathrm{~s}$ & $\mathrm{x}$ trans. & $4.26 \mathrm{~s}$ & $\mathrm{y}$ trans. & $2.69 \mathrm{~s}$ & Torsion \\
2 & $75.7 \mathrm{~m}$ & $1997 \mathrm{UBC}$ & $4.05 \mathrm{~s}$ & $\mathrm{x}+\mathrm{y}-$ trans. & $3.85 \mathrm{~s}$ & $\mathrm{x}+\mathrm{y}+$ trans. & $2.60 \mathrm{~s}$ & Torsion \\
3 & $78.3 \mathrm{~m}$ & $1997 \mathrm{UBC}$ & $4.01 \mathrm{~s}$ & $\mathrm{x}+\mathrm{y}+$ trans. & $3.95 \mathrm{~s}$ & $\mathrm{x}-\mathrm{y}+$ trans. & $2.82 \mathrm{~s}$ & Torsion \\
\hline \hline
\end{tabular}

frame located in the interior of Building 1 has been relocated to the exterior, eliminating the torsional eccentricity.

Building 3 is L-shaped in plan, as shown in Figures $6 \mathrm{c}$ and $6 \mathrm{f}$, with one elevator core serving both wings of the building. The wings have only two-bay moment frames across their ends and, as a result, are softer than the spine (reentrant corner region) of the building, which features three-bay and five-bay moment frames. The wings therefore have a tendency to flap during strong shaking. Out-of-phase shaking of the wings could lead to stress concentration at the reentrant corner and potential failure in a tearing mode. In-phase shaking of the wings could lead to twisting in the building and potential failure in a torsional mode. The UBC classifies such buildings as irregular and stipulates that they be designed for lateral forces that are approximately 10\% larger than those prescribed for regular buildings.

Detailed floor plans, beam and column sizes, and the gravity, wind, and seismic loading criteria are given in Krishnan et al. $(2005,2006)$ for Buildings 1 and 2 and in Krishnan (2003a, 2007) for Building 3. The periods of the fundamental modes for each building, obtained through eigenvalue analysis of the computational models, are given in Table 1 . The periods of the translational modes for Buildings 2 and 3, are significantly lower than for Building 1, illustrating the increased stiffness in the structural systems designed according to the more stringent requirements of the 1997 UBC. As expected, the plan irregularity in Building 3 results in a longer period for the torsional mode for Buildings 1 and 2.

\section{FINITE-ELEMENT MODELING OF STRUCTURAL RESPONSE}

Nonlinear damage analyses of the structures are performed using the program FRAME3D (http://virtualshaker.caltech.edu), which has been extensively validated against analytical solutions of simple problems and cyclic data from component tests, as well as pseudodynamic full-scale tests of assembled structures (Krishnan 2003b, 2009, 2010). FRAME3D incorporates material and geometric nonlinearity, which enables the modeling of the global stability of the building, accounting for $P-\Delta$ effects accurately. Beams are modeled using segmented elastofiber elements, with nonlinear end segments that are subdivided in the cross section into a number of fibers, and an interior elastic segment, as shown in Figure 7. The stress-strain response of each fiber in the nonlinear end-segment is hysteretic, including flexural yielding, strain-hardening and ultimately rupture of the fiber, as shown in Figure 8. Since strength and stiffness of the end segments of beams and columns are integrals of the corresponding quantities over all the fibers comprising the segment, they too can degrade as the stresses in the fibers exceed the ultimate stress and traverse the downhill path 


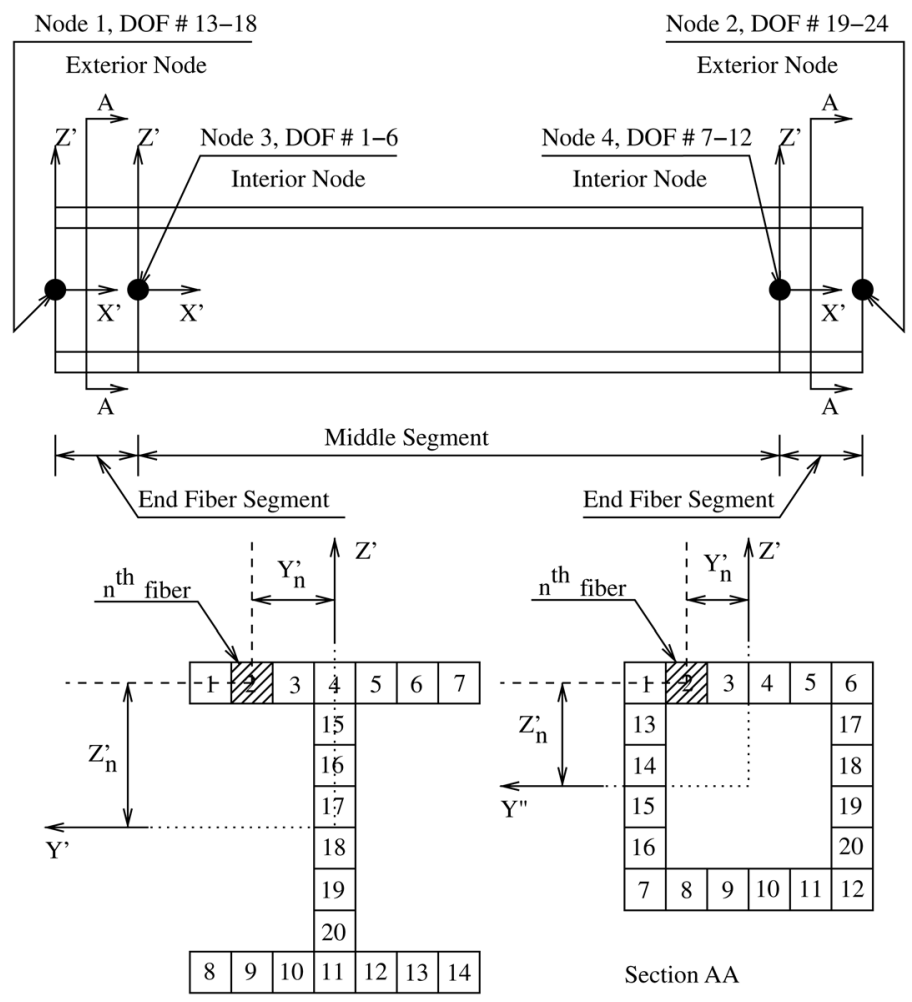

Figure 7. Schematic of the elastofiber beam element used to model columns and beams. Each element is divided into a linear elastic middle segment and two nonlinear fiber end segments, as shown in (a). The fiber segments are composed of 20 nonlinear fibers that run the length of the segment, as shown in the section view in (b).

to rupture. In the extreme event that all the fibers of the end segment rupture, there will be a complete severing of the column or beam. While fibers can fracture at randomly selected strain levels, low-cycle fatigue is not explicitly included. Neither is local-buckling of column flanges. Beam-to-column joints are modeled in three dimensions using panel zone elements that include shear yielding. These elements have been shown to simulate damage accurately and efficiently (Krishnan and Hall 2006a, 2006b).

Models for Buildings 1, 2, and 3 use panel zone elements and elastofiber elements to model the structural frame, and plane stress elements to represent the floor diaphragms. Composite action due to the connection between the floor slabs and the moment-frame beams is not considered. The story masses, computed using $100 \%$ of the design dead load and $30 \%$ of the design live load, are lumped at the column locations based on plan tributary area. A rigid foundation is assumed, with the base of all columns fixed. Soil-structure interaction is not included.

There is great uncertainty in the performance of the beam-to-column connections in welded steel moment-frame buildings, as evidenced in the 1994 Northridge earthquake, 


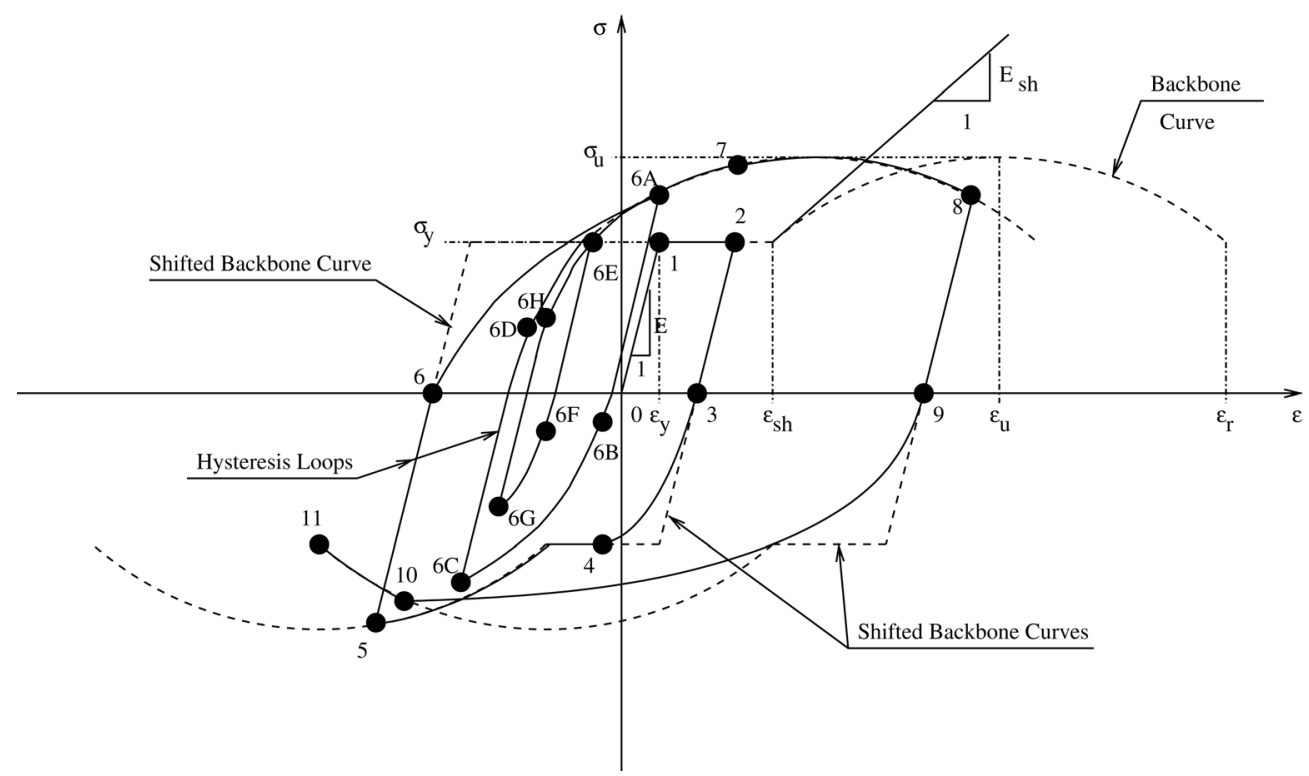

Figure 8. Hysteretic stress-strain relationship that governs the response of each nonlinear fiber in the elastofiber element illustrated in Figure 7.

where brittle failure was observed in many of these connections, as shown in Figure 9. Consequently, the fracture mode of failure is also included and is used here to consider the effect of fracture-susceptible connections on overall building response.

Two models are considered for each building, one with perfect connections, and the other with susceptible connections. To model brittle failure of the welded connections, a fracture strain level is prescribed for the fibers comprising the nonlinear end segments of the beam elements, as shown in Figure 10a. When this strain level is exceeded for a given fiber, it is considered to be "fractured" and can no longer resist tensile forces, though it can resist
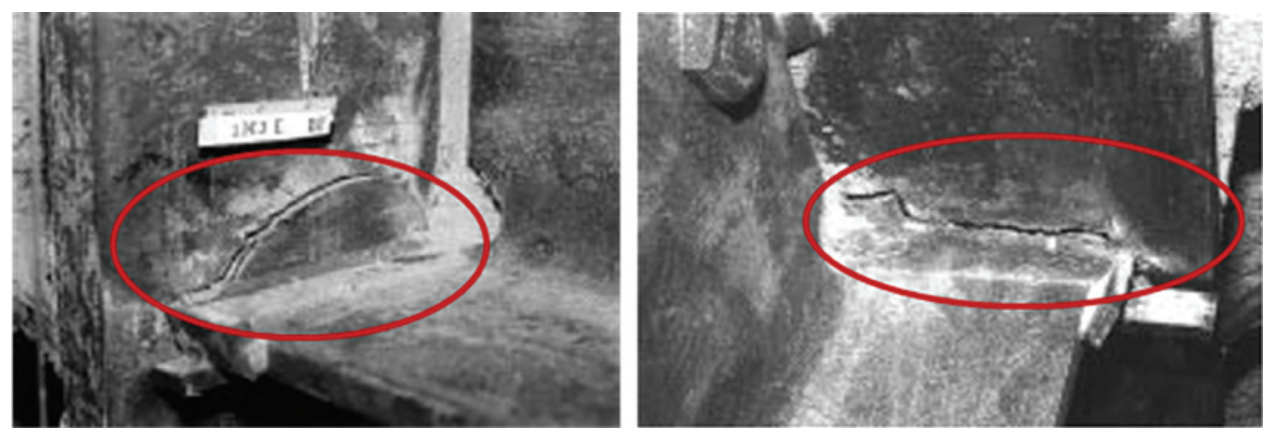

Figure 9. Examples of brittle failure of welded beam-column connections during the 1994 Northridge earthquake. 

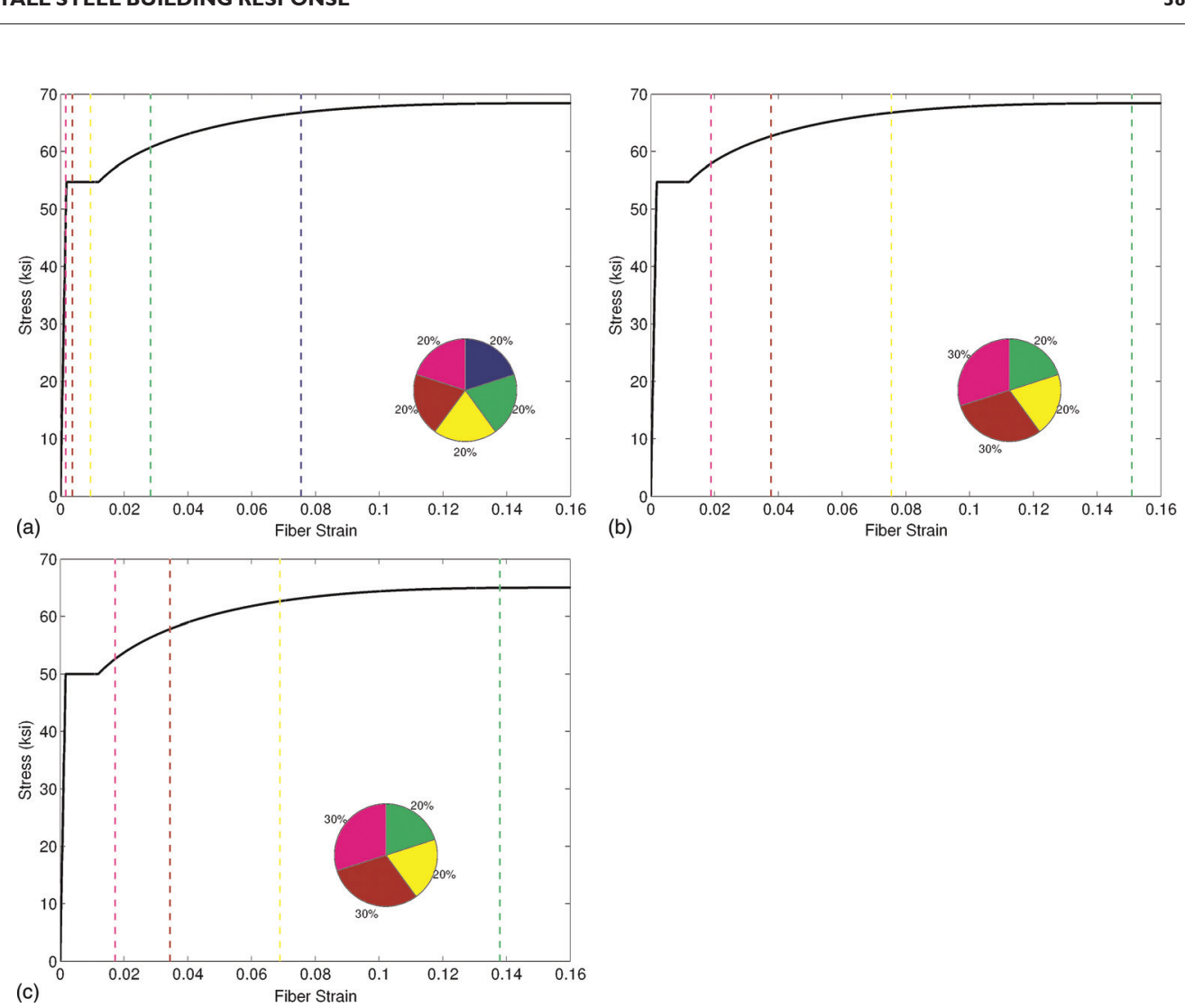

(c)

Figure 10. Marked on the backbone axial stress-strain curves of the elastofiber element fibers is the distribution of fracture strain assumed for the susceptible connection case of Building 1 [(a) beam bottom flange, and (b) beam web and top flange] and Buildings 2 and 3 [(c) top and bottom flanges, as well as the web]. The pie chart shows the probability of assigning one of the five fracture strains marked on the backbone curve to a given fiber, for e.g., in (a) there is a $20 \%$ chance that the fiber fracture strain is about 0.028 , as indicated by the green dashed line and the green-colored section in the pie chart.

compressive forces. Fractures strain values for each elastofiber element are randomly assigned according to a user-defined probability distribution. For Building 1, the fracture strain for the fibers in the bottom-flanges of moment-frame beams, represented by fibers 8 to 14 in Figure $7 \mathrm{a}$, is drawn from the distribution shown in Figure 10a (probability is 20\% that the fracture strain is 0.9 times the yield strain, $\varepsilon_{y} ; 20 \%$ that it is $2 \varepsilon_{y} ; 20 \%$ that it is $5 \varepsilon_{y}$; $20 \%$ that it is $15 \varepsilon_{y}$; and $20 \%$ that it is $40 \varepsilon_{y}$ ). For the top-flanges, represented by fibers $1-7$ in Figure $7 \mathrm{a}$, and the webs of the beams, represented by fibers 15-20 in Figure 7a, fracture strains are drawn from the distribution shown in Figure 10b (with a 30\% probability that the fracture strain is $10 \varepsilon_{y} ; 30 \%$ that it is $20 \varepsilon_{y} ; 20 \%$ that it is $40 \varepsilon_{y}$; and $20 \%$ that it is $80 \varepsilon_{y}$ ). For column flange and web fibers, it is assumed that the fracture strains are far greater than the rupture strain, thus precluding the occurrence of fractures. 
The specifications (FEMA 2000a) developed by the Federal Emergency Management Agency (FEMA) for moment-frame construction following the Northridge earthquake should result in superior connection performance, and hence, the connections in the buildings designed according to UBC97 are assumed to be less vulnerable to fracture than for the older Building 1. For the susceptible connection cases of Buildings 2 and 3, it is assumed that the fracture strain for all fibers (top and bottom flanges, as well as the web) is drawn from the distribution shown in Figure 10c, which is the same as that used for the top-flanges of the moment-frame beams in Building 1. Differences in the actual values of the fracture strain are due to differences in the yield strains of the steel used in the two types of buildings. It should be noted that the lack of a sufficiently large data set on fractured connections, combined with the great variety of factors affecting the behavior of beam-to-column connections, means that the probability distributions assumed in this study are not very reliable, and as-built connections may either be more or less vulnerable to fracture.

All the base models are accessible through the Caltech Virtual Shaker (http://virtualshaker. caltech.edu), a Science and Engineering gateway with a database of building models that can be downloaded, edited, and analyzed remotely on a computing cluster at Caltech using FRAME3D.

\section{EVALUATING MODEL PERFORMANCE}

At each of the 784 sites, analyses were performed using FRAME3D for the three building models, with perfect and fracture-susceptible connections and in two different orientations (with the $x$-axis in Figure 6 oriented in the east-west direction and rotated 90 degrees for Buildings 1 and 2 and 45 degrees for Building 3) for a total of 9,408 3-D nonlinear response history analyses. In each case, detailed structural damage as well as the displacements and interstory drifts are calculated. To assess the performance of these buildings, we use the performance levels defined by FEMA 356 (FEMA 2000c): Immediate Occupancy (IO), where very limited structural damage has occurred; Life Safety (LS), a damage state that includes damage to structural components but retains a finite margin against collapse; and Collapse Prevention (CP), a damage state at which the structure continues to support gravity loads but retains no margin against collapse. For existing buildings, the interstory drift ratio (IDR) limits for the IO, LS, and CP performance levels specified by FEMA are $0.007,0.025$, and 0.05 , respectively. These numbers were not intended to be hard criteria upon which performance would be judged. Nevertheless, in the absence of other criteria, they provide a basis for performance assessment. In addition to these criteria, the ShakeOut planners were interested in knowing when a building would be red-tagged. In thousands of collapse analyses conducted by the authors on models such as the ones considered in this study, a large percentage of models lose stability (i.e., stiffness matrix ill-conditioning) beyond peak IDRs of 0.10 . Thus, peak transient IDRs greater than 0.10 would almost surely result in complete collapse. Given that the models do not include certain critical failure modes such as local buckling in column flanges, the peak IDR range of 0.075-0.100 (CO) may be indicative of partial to complete collapse (unstable). Models with intermediate peak IDRs in the range of $0.050-0.075$ are assumed to be on the verge of collapse (neutrally stable) and hence may be red-tagged (RT). The large IDR range for structures on the verge of collapse is reflective of the uncertainties associated with collapse predictions, as well as the 

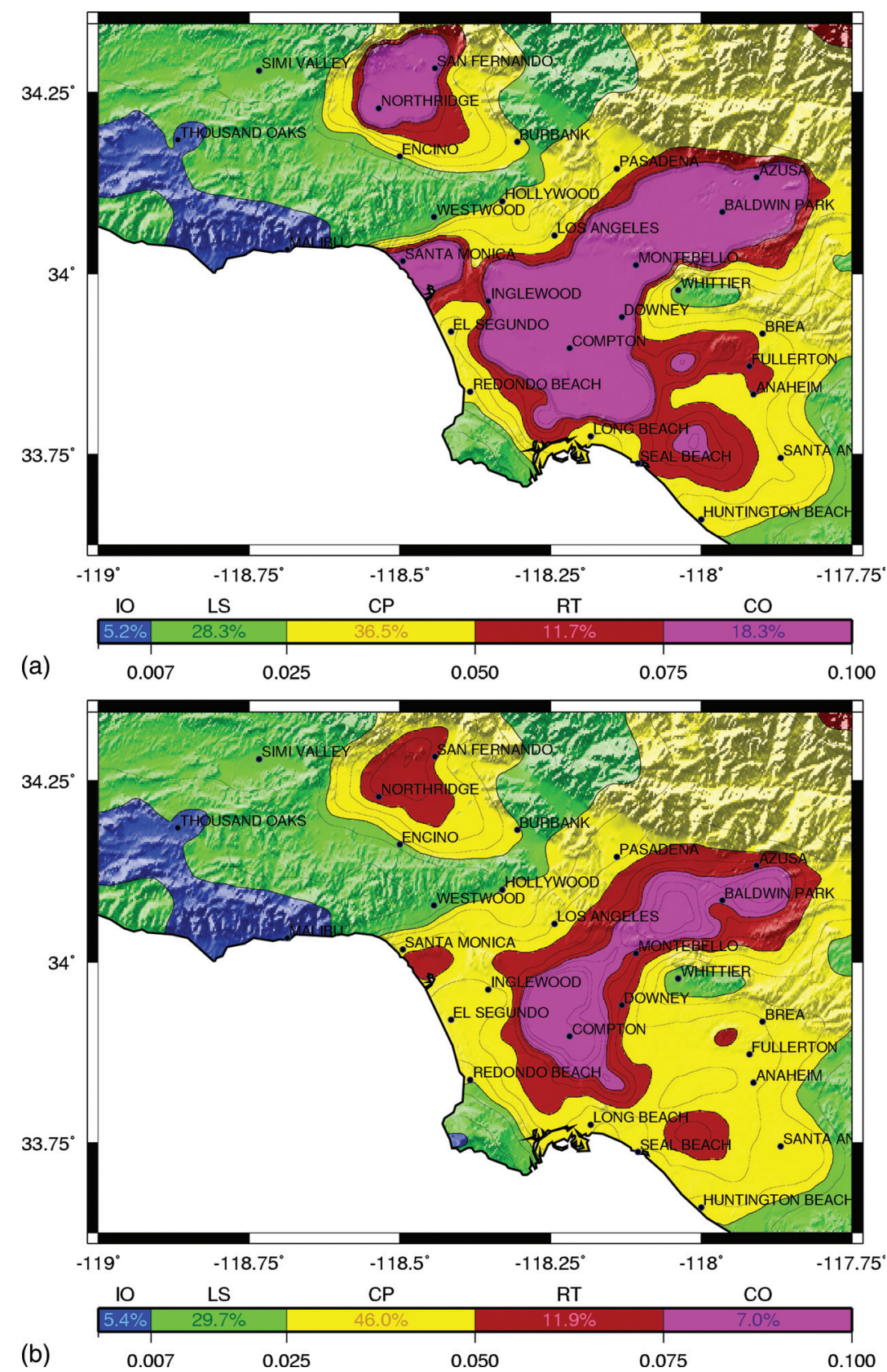

Figure 11. Maps of peak IDR for Building 1 with (a) susceptible and (b) perfect connections, Building 2 with (c) susceptible and (d) perfect connections, and Building 3 with (e) susceptible and (f) perfect connections. Each model is in its base orientation. Color-coding corresponds to performance classification: Immediate Occupancy (IO); Life-Safety (LS); Collapse Prevention (CP); Red-Tagged (RT); Collapse (CO). 

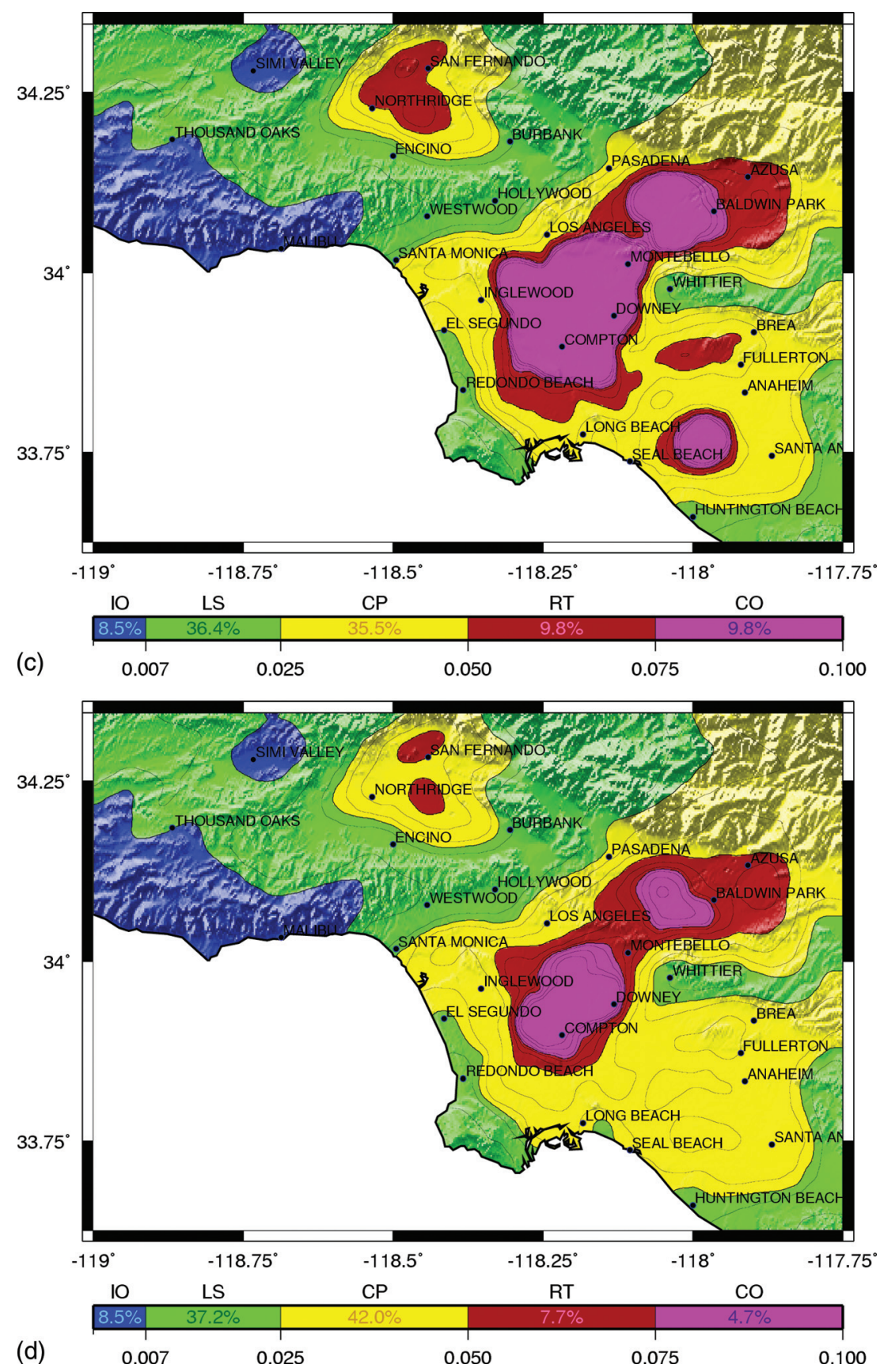

Figure 11. (Continued) 

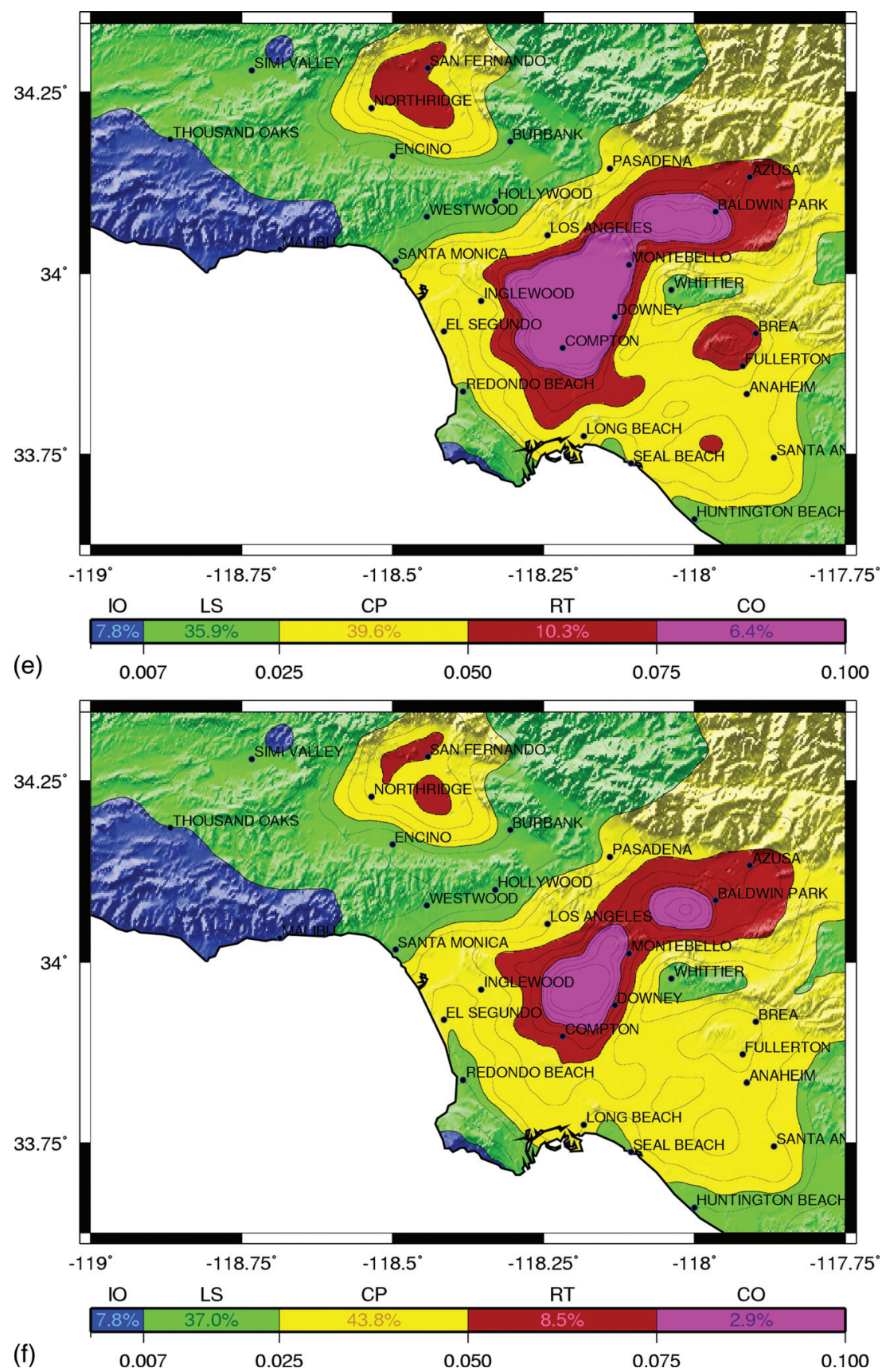

Figure 11. (Continued) 
Table 2. Building performance (percentage of analysis sites falling into a given performance category) in base and rotated orientations, with susceptible and perfect beam-to-column connections. Numbers indicate the percentage of analysis sites at which performance can be categorized as: (a) immediately occupiable (IO); (b) life-safe (LS); (c) collapse-prevention (CP); (d) red-tagged (RT); or (e) collapsed (CO)

\begin{tabular}{|c|c|c|c|c|c|c|c|}
\hline \multirow[b]{2}{*}{ Model } & \multirow[b]{2}{*}{ Orientation } & \multirow[b]{2}{*}{ Connections } & \multicolumn{5}{|c|}{ Performance Category ( $\%$ of 784 analysis sites) PGA (g) } \\
\hline & & & IO & LS & $\mathrm{CP}$ & RT & $\mathrm{CO}$ \\
\hline \multirow{4}{*}{$\begin{array}{l}\text { Building 1 } \\
\text { (Existing) } \\
\text { (1982 UBC) }\end{array}$} & \multirow[t]{2}{*}{ Base } & Susceptible & 5.2 & 28.3 & 36.5 & 11.7 & 18.3 \\
\hline & & Perfect & 5.4 & 29.7 & 46.0 & 11.9 & 7.0 \\
\hline & \multirow[t]{2}{*}{ Rotated } & Susceptible & 4.8 & 29.7 & 33.8 & 7.5 & 24.2 \\
\hline & & Perfect & 4.9 & 31.0 & 42.2 & 10.7 & 11.3 \\
\hline \multirow{4}{*}{$\begin{array}{l}\text { Building } 2 \\
\text { (1997 UBC) }\end{array}$} & \multirow[t]{2}{*}{ Base } & Susceptible & 8.5 & 36.4 & 35.5 & 9.8 & 9.8 \\
\hline & & Perfect & 8.5 & 37.2 & 42.0 & 7.7 & 4.7 \\
\hline & \multirow[t]{2}{*}{ Rotated } & Susceptible & 7.7 & 36.0 & 36.0 & 8.2 & 12.1 \\
\hline & & Perfect & 7.7 & 37.4 & 41.2 & 10.0 & 3.8 \\
\hline \multirow{4}{*}{$\begin{array}{l}\text { Building } 3 \\
\text { (1997 UBC) } \\
\text { (L-shaped) }\end{array}$} & \multirow[t]{2}{*}{ Base } & Susceptible & 8.2 & 42.4 & 39.0 & 6.6 & 3.9 \\
\hline & & Perfect & 8.2 & 42.8 & 40.9 & 6.6 & 1.5 \\
\hline & \multirow[t]{2}{*}{ Rotated } & Susceptible & 9.9 & 45.5 & 34.2 & 4.6 & 5.7 \\
\hline & & Perfect & 9.9 & 46.0 & 35.9 & 5.5 & 2.7 \\
\hline
\end{tabular}

Table 3. Peak interstory drift ratios for each building model when located at the 14 identified clusters of existing high-rise buildings

\begin{tabular}{|c|c|c|c|c|c|c|c|}
\hline \multirow[b]{2}{*}{ Location } & \multicolumn{2}{|c|}{ Building 1} & \multicolumn{2}{|c|}{ Building 2} & \multicolumn{2}{|c|}{ Building 3} & \multirow[b]{2}{*}{ Average } \\
\hline & Perf. & Susc. & Perf. & Susc. & Perf. & Susc. & \\
\hline Canoga Park & 0.016 & 0.016 & 0.014 & 0.014 & 0.013 & 0.013 & 0.014 (LS) \\
\hline Encino & 0.030 & 0.030 & 0.020 & 0.020 & 0.016 & 0.016 & $0.022(\mathrm{LS})$ \\
\hline Universal City & 0.025 & 0.025 & 0.016 & 0.016 & 0.013 & 0.013 & $0.018(\mathrm{LS})$ \\
\hline Glendale & 0.025 & 0.025 & 0.017 & 0.017 & 0.015 & 0.015 & 0.019 (LS) \\
\hline Pasadena & 0.035 & 0.037 & 0.027 & 0.027 & 0.027 & 0.027 & $0.030(\mathrm{CP})$ \\
\hline Santa Monica & 0.048 & 0.076 & 0.020 & 0.020 & 0.019 & 0.019 & $0.034(\mathrm{CP})$ \\
\hline Century City & 0.029 & 0.036 & 0.018 & 0.018 & 0.018 & 0.018 & $0.023(\mathrm{LS})$ \\
\hline Park La Brea & 0.032 & 0.040 & 0.023 & 0.023 & 0.022 & 0.022 & $0.027(\mathrm{CP})$ \\
\hline Hollywood & 0.027 & 0.029 & 0.017 & 0.017 & 0.017 & 0.017 & 0.021 (LS) \\
\hline Downtown Los Angeles & 0.030 & 0.033 & 0.031 & 0.032 & 0.031 & 0.031 & $0.031(\mathrm{CP})$ \\
\hline El Segundo & 0.031 & 0.042 & 0.026 & 0.030 & 0.025 & 0.026 & $0.030(\mathrm{CP})$ \\
\hline Long Beach & 0.031 & 0.035 & 0.024 & 0.028 & 0.023 & 0.025 & $0.028(\mathrm{CP})$ \\
\hline Anaheim-Santa Ana & 0.041 & 0.044 & 0.031 & 0.031 & 0.025 & 0.025 & $0.033(\mathrm{CP})$ \\
\hline Irvine & 0.029 & 0.031 & 0.024 & 0.025 & 0.025 & 0.025 & $0.026(\mathrm{CP})$ \\
\hline
\end{tabular}




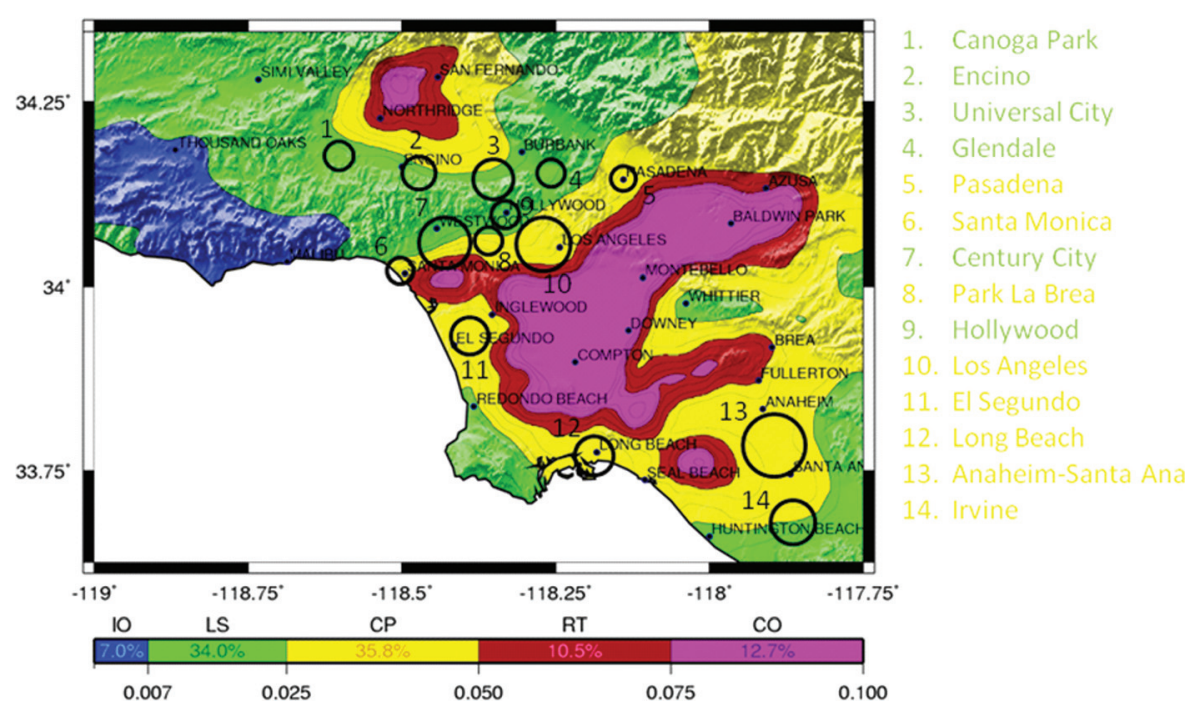

Figure 12. Averaged performance for all models, orientations, and beam-column connection conditions, with the 14 clusters of existing high-rise buildings indicated. Average building performance in each cluster is indicated by the shading of the names.

uncertainties associated with the myriad of field conditions, subtle differences in which can result in vastly different outcomes in as far as collapse is concerned.

Maps of peak interstory drift ratios for the base orientation of the three buildings assuming fracture-susceptible connections are shown in Figures 11a, 11c, and 11e. Corresponding maps assuming perfect connections are shown in Figures $11 \mathrm{~b}, 11 \mathrm{~d}$, and $11 \mathrm{f}$. The colorcoding on the maps follows the previously described performance criteria. The performance of all buildings is summarized in Table 2. Building 1 exhibits the worst performance with the susceptible connection model collapsing at $18.3 \%$ of the analysis sites and being redtagged at $11.7 \%$ of the sites. The L-shaped Building 3 performs the best with the percentage of collapsed and red-tagged instances being $10.3 \%$ and $6.4 \%$, respectively. The performance of Building 2 is only slightly worse than Building 3. If we assume that the beam-tocolumn connections are perfect, then there is a significant drop in the number of collapsed and red-tagged buildings. In the rotated orientation, performance is slightly worse for Buildings 1 and 2 and slightly better for Building 3, as shown in Table 2. However, the spatial contours of building performance in the corresponding peak interstory drift maps are not significantly altered from those shown in Figures 11a-11f.

\section{CONCLUSIONS}

The performance for each building model and connection susceptibility case at the locations of the 14 clusters of existing high-rise buildings is summarized in Table 3. Note that values in this table represent an average of the two considered orientations for each model, 
as orientation did not significantly impact performance. We observe that for Building 1, performance is classified as collapse-prevention (CP) or worse for all sites except Canoga Park, for perfect and fracture-susceptible connections. At one site (Santa Monica) the performance of Building 1 with susceptible connections is classified as potentially collapsing (CO). Performance for the buildings designed to the 1997 UBC is significantly improved, with many clusters falling into the Life-Safety (LS) category, but areas such as Pasadena, downtown Los Angeles, El Segundo, Long Beach, Anaheim-Santa Ana, and Irvine are classified as CP. The final column in Table 3 gives the averaged peak IDR and performance level for each tall-building cluster location. Six of the clusters have an average performance level of LS, while the remaining eight are classified as CP.

Looking at the average model response, shown in Figure 12, it is immediately apparent that with a slightly different scenario earthquake, model performance would have been far worse. Building clusters located in Santa Monica, downtown Los Angeles and Century City are all located within ten kilometers of regions of red-tagging and potential collapse. What this means is that given a different set of earthquake source parameters, it is entirely possible that at least some of these locations may end up in the red or pink zones indicating collapses or the need for red-tagging. As shown in Krishnan et al. (2006) differences in the hypocenter location, slip distribution, rupture directivity, and the velocity model result in a dramatically different distribution of building damage. Bearing this in mind, it was recommended that the ShakeOut drill be planned with a damage scenario comprising of $5 \%$ of the estimated 150 steel moment-frame structures in the 10-30 story range collapsing ( 8 collapses), 10\% of the structures red-tagged (16 redtagged buildings), $15 \%$ of the structures with damage serious enough to cause loss of life ( 24 buildings in the yellow zone with fatalities), and $20 \%$ of the structures with visible damage requiring building closure (32 buildings with visible damage and possible injuries) (Krishnan and Muto 2008). These recommendations were presented to a panel of one academic researcher and two practicing engineers, who concluded that realistically one or more collapses could occur, given the intensity of the motions during the scenario earthquake.

The actual ShakeOut drill featured 5 collapses of tall buildings, 10 red-tagged buildings, and 20 buildings with serious damage and possible fatalities (Jones et al. 2008). Building collapses were located near four existing high-rise building sites falling within the $\mathrm{CO}$ zone in Figure 12, and one site located outside the study region in San Bernardino. It should be emphasized that the collapsed buildings in the scenario are entirely hypothetical and their proximity to real, nearby high-rise buildings does not imply anything about the likely performance of the real buildings.

This work is an example of the unprecedented level of scientific support for the planning of the ShakeOut Scenario, as advances in computational seismology and structural engineering were combined to attempt to paint a realistic picture of the potential consequences of a large seismic event on the southern San Andreas Fault. An additional benefit of large-scale studies such as this one is the opportunity to gain significant insight into the seismic behavior of the chosen structures and to generate building fragility functions for use in performance-based earthquake engineering (Porter et al. 2007), as demonstrated in Appendix B. 


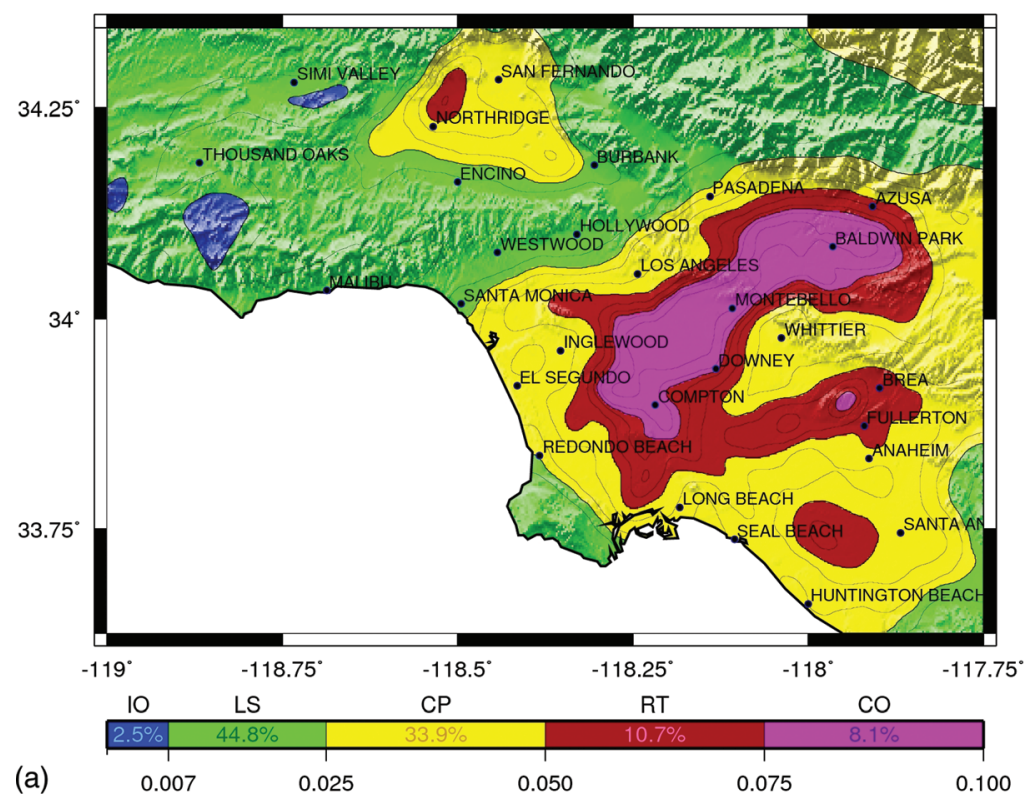

(a)

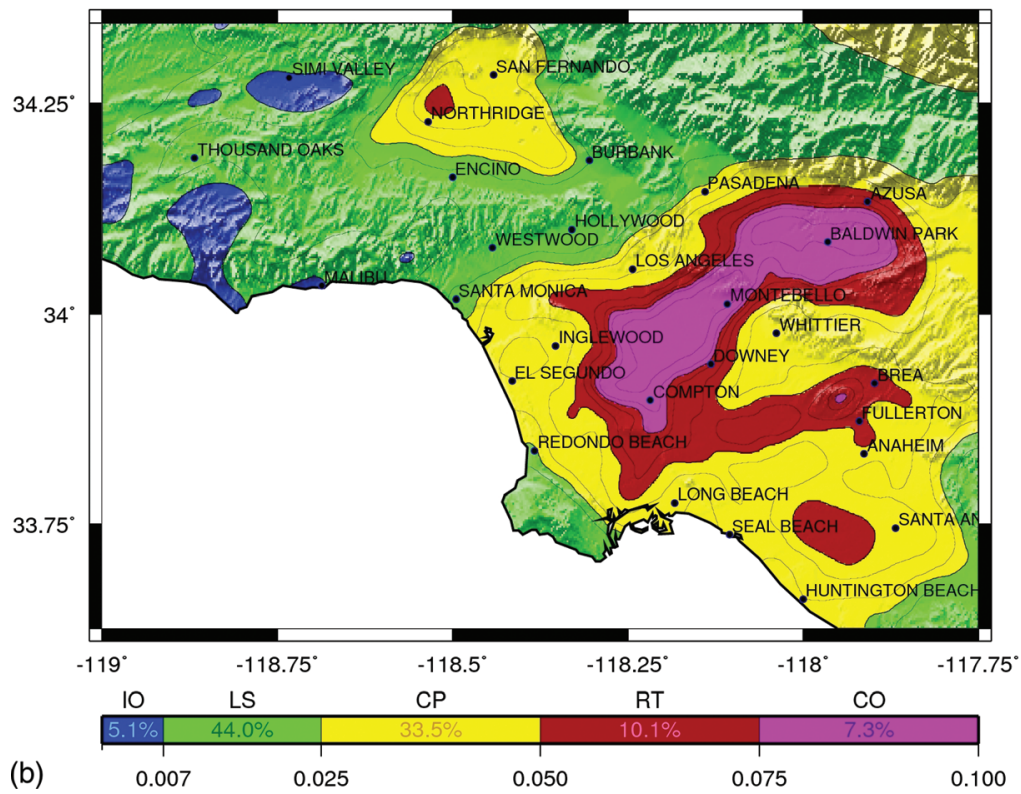

Figure A1. Map of peak IDR for Building 2 in the base orientation with perfect connections, subjected to (a) the broadband ShakeOut v1.2 simulated ground motions, (b) the v1.2 motions low-pass filtered at $0.5 \mathrm{~Hz}$. Color-coding corresponds to performance classification: Immediate Occupancy (IO); Life-Safety (LS); Collapse Prevention (CP); Red-Tagged (RT); Collapse (CO). A map of peak IDR for this model subjected to the long-period simulated motions used in this study is shown in Figure 11d. 


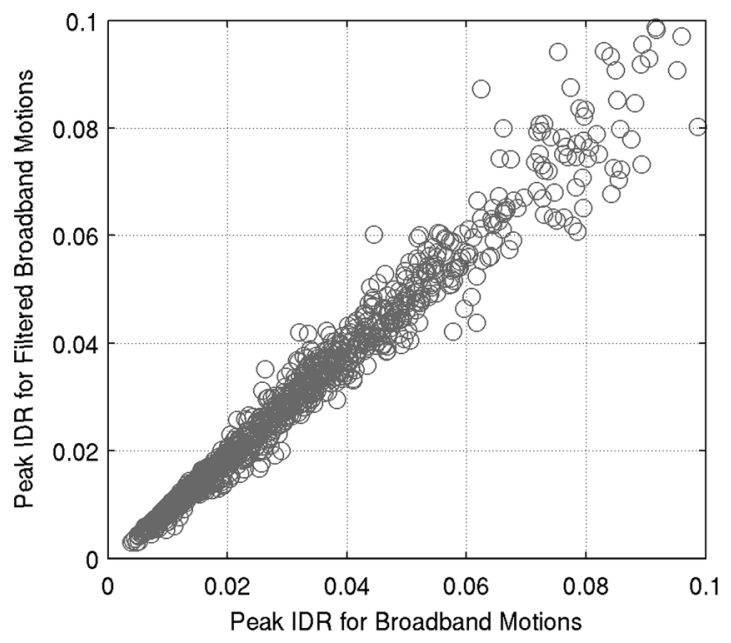

Figure A2. Comparison of the peak IDR for Building 2 (perfect connections, base orientation) subjected to the broadband ShakeOut motions and the peak IDR for the same model subject to those motions low-pass filtered at $0.5 \mathrm{~Hz}$.

\section{APPENDIX A}

The analyses performed for this study uses the preliminary ShakeOut v1.1 long-period simulated ground motions (limited to periods greater than $2 \mathrm{~s}$ ), rather than the final v1.2 synthetic time histories, which included periods greater than $0.1 \mathrm{~s}$ (Graves et al. 2008). This was primarily due to time constraints for delivering recommendations to the ShakeOut Scenario planners. A preliminary study of the effect of the high-frequency content in the ShakeOut ground motions has been performed. The Building 2 model, in the base orientation with perfect connections, was subjected to the ShakeOut v1.2 ground motions for the study region, and the v1.2 motions low-pass filtered at $0.5 \mathrm{~Hz}$. Figures Ala and A1b show maps of peak IDR for the selected model subjected to the unfiltered and filtered v1.2 motions, respectively. The geographical distribution of building response is very similar.

Table A1. Mean $\mu$ and logarithmic standard deviation $\sigma$ of the fragility functions for the RT (red-tagged) and CO (collapsed) damage states for the three building models with perfect and susceptible connections

\begin{tabular}{|c|c|c|c|c|c|c|c|c|}
\hline \multirow[b]{3}{*}{ Bldg. } & \multicolumn{4}{|c|}{ Perfect Connections } & \multicolumn{4}{|c|}{ Susceptible Connections } \\
\hline & \multicolumn{2}{|c|}{$\mathrm{RT}$} & \multicolumn{2}{|c|}{$\mathrm{CO}$} & \multicolumn{2}{|c|}{ RT } & \multicolumn{2}{|c|}{$\mathrm{CO}$} \\
\hline & $\mu$ & $\sigma$ & $\mu$ & $\sigma$ & $\mu$ & $\sigma$ & $\mu$ & $\sigma$ \\
\hline 1 & 82.04 & 0.2614 & 115.39 & 0.3464 & 75.45 & 0.2278 & 108.28 & 0.3670 \\
\hline 2 & 102.91 & 0.1677 & 158.42 & 0.2807 & 90.84 & 0.1964 & 131.22 & 0.2965 \\
\hline 3 & 107.68 & 0.1537 & 165.37 & 0.1752 & 94.90 & 0.1925 & 143.85 & 0.2425 \\
\hline
\end{tabular}



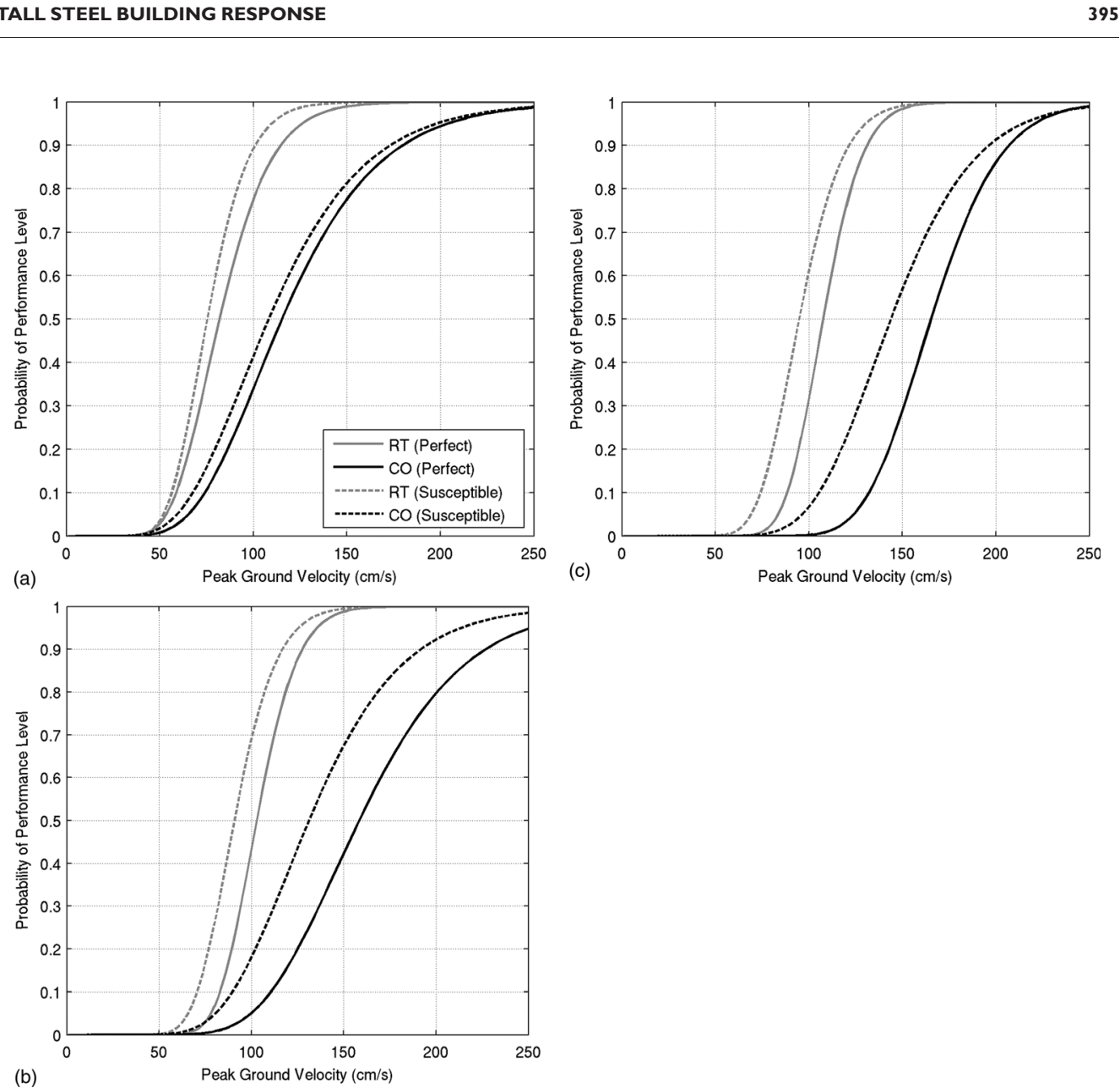

(c)

Figure A3. Fragility curves for the probability of RT (Red-Tagged) and CO (Collapse) states as a function of peak ground velocity for (a) Building 1, (b) Building 2, and (c) Building 3, for the perfect connection and fracture-susceptible connection cases.

Figure A2 plots the peak IDR for the model subjected to the filtered records against the peak IDR resulting from the unfiltered v1.2 records. The coefficient of correlation is 0.95 (increasing to 0.99 if we consider only peak IDRs less than 0.1 ), indicating that higher frequency motions have a limited contribution to the response of this long-period structure. Krishnan et al. (2006) performed a similar study, examining the effect of higher-frequency ground motion (periods $<2 \mathrm{~s}$ ) on the response of Buildings 1 and 2 by comparing peak IDRs due to broadband ground motion recorded in the Chi-Chi and Hokkaido earthquakes against that due to the same records with the higher frequencies filtered out, and came to the same conclusion. Note that filtered v1.2 motions are not directly comparable to the v1.1 motions used in this study, as the ShakeOut v1.2 motions were simulated using a different rupture model and applying a site correction function that was not used for the long period motions, and were also generated on a different grid of coordinate points. 


\section{APPENDIX B}

The structural model responses to the simulated ground motions were used to develop fragility functions (Porter et al. 2007) that show the probability of a given performance level (as described in "Evaluating Model Performance") based on the peak horizontal ground velocity. The curves are lognormal cumulative distribution functions with the lognormal mean and standard deviation given by a least-squares fit to the binary data (whether or not the model response falls in the chosen performance category), summarized in Table A1. Figures A3a, b, and c show fragility curves for the RT and CO states for Buildings 1, 2, and 3, considering both the perfect connection and fracture-susceptible connection cases.

\section{ACKNOWLEDGMENTS}

We wish to acknowledge the financial support provided by the United States Geological Survey for conducting this study. Our thanks go to Brad Aagaard, Ken Hudnut, Lucy Jones, and Dale Cox of the USGS, Rob Graves of URS, and Keith Porter of the University of Colorado at Boulder for contributing important elements and ideas to this study. Our thanks also go to members of the ShakeOut structural panel, Greg Deierlein of Stanford University, Ron Hamburger of Simpson, Gumpertz \& Heger, and Jim Malley of Degenkolb, for their feedback and comments. The authors wish to thank the associate editor and reviewers for providing valuable feedback which have served to enhance the article.

\section{REFERENCES}

Emporis Corporation (Emporis), 2007. Emporis Research, www.emporis.com. [viewed 19 June 2007]

Federal Emergency Management Agency (FEMA), 2000a. Recommended Specifications and Quality Assurance Guidelines for Steel Moment Frame Construction for Seismic Applications, Tech. Rep. FEMA-353, Washington, D.C.

Federal Emergency Management Agency (FEMA), 2000b. State of the Art Report on the Past Performance of Steel Buildings Moment Frame Buildings in Earthquakes, Tech. Rep. FEMA-355E, Washington, D.C.

Federal Emergency Management Agency (FEMA), 2000c. Prestandard and Commentary for the Seismic Rehabilitation of Buildings. Tech. Rep. FEMA-356, Washington, D.C.

Graves, R., Aagaard, B., Hudnut, K., Star, L., Stewart, J., and Jordan, T., 2008. Broadband simulation for $\mathrm{M}_{\mathrm{w}} 7.8$ southern San Andreas earthquakes: Ground motion sensitivity to rupture speed, Geophysical Research Letters 35, L22302, doi:10.1029/2008GL035750.

Graves, R., Aagaard, B., and Hudnut, K, 2011. The ShakeOut earthquake source and ground motion simulations, Earthquake Spectra 27, 273-291.

Hudnut, K. W., Jones, L. M., and Aagaard, B. T., 2007. The Southern California Shakeout Scenario, part 1: Earth science specification of a Big One, Annual Meeting of the Seismological Society of America, Abstract reference number 07-501.

Jones, L. M., Bernknopf, R., Cox, D., Goltz, J., Hudnut, K., Mileti, D., Perry, S., Ponti, D., Porter, K., Reichle, M., Seligson, H., Shoaf, K., Treiman, J., and Wein, A., 2008. The ShakeOut Scenario: USGS Open File Report 2008-1150 and California Geological Survey Preliminary Report 25, http://pubs.usgs.gov/of2008/1150 and http://conservation.ca.gov/cgs, Sacramento, CA. 
Kohler, M., Magistrale, H., and Clayton, R., 2003. Mantle heterogeneities and the SCEC threedimensional seismic velocity model version 3, Bulletin of the Seismological Society of America 93, 757-774.

Krishnan, S., 2003a. Three-Dimensional Nonlinear Analysis of Tall Irregular Steel Buildings Subject to Strong Ground Motion: Tech. Rep. EERL 2003-01, Earthquake Engineering Research Laboratory, California Institute of Technology, Pasadena, CA.

Krishnan, S., 2003b. FRAME3D-A Program for Three-Dimensional Nonlinear Time-History Analysis of Steel Buildings: User Guide: Tech. Rep. EERL 2003-03, Earthquake Engineering Research Laboratory, California Institute of Technology, Pasadena, CA.

Krishnan, S., 2009. On the Modeling of Elastic and Inelastic, Critical and Post-Buckling Behavior of Slender Column and Bracing Members, Technical Report Caltech EERL-2009-03, California Institute of Technology, Pasadena, CA.

Krishnan, S., 2010. The modified elastofiber element for steel slender column and brace modeling, Journal of Structural Engineering 136, 1350-1366.

Krishnan, S., and Hall, J. F., 2006a. Modeling steel frame buildings in three dimensions -Part I: Panel zone and plastic hinge beam elements, Journal of Engineering Mechanics 132, 345-358.

Krishnan, S., and Hall, J. F., 2006b. Modeling steel frame buildings in three dimensions-Part II: Elastofiber beam element and examples, Journal of Engineering Mechanics 132, 359-374.

Krishnan, S., Ji, C., Komatitsch, D., and Tromp, J., 2005. Performance of 18-story Steel Moment Frame Buildings during a Large San Andreas Earthquake-A Southern CaliforniaWide End-to-End Simulation: Tech. Rep. EERL 2005-01, Earthquake Engineering Research Laboratory, California Institute of Technology, Pasadena, CA.

Krishnan, S., Ji, C., Komatitsch, D., and Tromp, J., 2006. Performance of two 18-story steel moment frame buildings in Southern California during two large simulated San Andreas earthquakes, Earthquake Spectra 22, 1035-1061.

Krishnan, S., 2007. Case studies of damage to 19-story irregular steel moment frame buildings under near-source ground motion, Earthquake Engineering and Structural Dynamics 36, 861-885.

Krishnan, S., and Muto, M., 2008. SHAKEOUT 2008: Tall Steel Moment Frame Building Response: Technical Report to the USGS, California Institute of Technology, Pasadena, CA.

Magistrale, H., Day, S., Clayton, R., and Graves, R., 2000. The SCEC Southern California reference three-dimensional seismic velocity model version 2, Bulletin of the Seismological Society of America 90, S65-S76.

Magistrale, H., McLaughlin, K., and Day, S., 1996. A geology-based 3-D velocity model of the Los Angeles basin sediments, Bulletin of the Seismological Society of America 86, 1161-1166.

Porter, K., Kennedy, R., and Bachman, R., 2007. Creating fragility functions for performancebased earthquake engineering, Earthquake Spectra 23, 471-489.

Porter, K., Jones, L., Cox, D., Goltz, J., Hudnut, K., Perry, S., Ponti, D., Reichle, M., Rose, A., Scawthorn, C., Seligson, H., Shoaf, K., Treiman, J., and Wein, A., 2011. The ShakeOut Scenario: A hypothetical $\mathrm{M}_{\mathrm{w}} 7.8$ earthquake on the southern San Andreas Fault, Earthquake Spectra 27, 239-261.

Star, L. M., Stewart, J. P., Graves, R. W., and Hudnut, K. W., 2008. Validation against NGA empirical model of simulation motions for M7.8 rupture of San Andreas Fault, Paper No. 020070, $14^{\text {th }}$ World Conference on Earthquake Engineering, October 12-17, 2008, Beijing, China. 
Structural Engineers Association of California (SAC), 1995. Analytical and Field Investigations of Buildings Affected by the Northridge Earthquake of January 17, 1994-Part 2: Tech. Rep. SAC 95-04, Part 2, Applied Technology Council and California Universities for Research in Earthquake Engineering.

(Received 4 May 2009; accepted 11 January 2010) 